\title{
Stages in Formalizing Energy Conservation and Efficiency Management in Industrial Enterprises
}

\author{
Melnik A.N. \\ Ermolaev K.A. \\ Antonova N.V.
}

Kazan Federal University, Kazan, 420008, Russia

\section{Doi:10.5901/mjss.2014.v5n12p173}

\begin{abstract}
This study introduces a method to formalize mathematical target setting at managing energy conservation and efficiency in enterprises. The suggested approach is based on energy conservation positioning, which reflects the link between company's management team and its energy efficiency policy. This project implementation aims to increase competitiveness of enterprises in a range of industries.
\end{abstract}

Keywords: energy efficiency, sustainable manufacturing, simulation, energy behavior, firm behavior, industrial energy programs, management practices

\section{Introduction}

Energy efficiency improvement is one of the major problems in industrial enterprise policy worldwide [1]. However there is a number of unsettled problems, basically methodological and methodical, which hinder its implementation. These are seen as reasons for the interest in finding solutions on the part of the academic community.

We conducted a survey on approaches to the issue, which indicated that special attention is paid to finding out cause and effect relationship between economic growth and power consumption in a certain industry. We propose a number of approaches based on the results of our survey. These approaches are aimed at forming business mechanisms to create energy efficient production systems at all levels, from a single engineering process to a global supply intercompany chain $[2-5,11]$. The question of economical motivation in order to increase energy efficiency in the factories under investigation is of considerable interest. [6-8]. A separate line of the research investigates different aspects of creating energy conservation programs for enterprises belonging to different lines of business $[9,10]$.

Another important aspect of the study is focused on behavior determinant and possible action strategies of power resources consumer. The study [12] provides an extended analytical review of different methodological approaches to energy policy management worldwide, which consists in meeting the desired results i.e. increasing energy efficiency. American analysts in their studies investigate energy saving policy of the companies' management teams and substantiate significance of the top manager's role in achieving significant energy efficiencies [13]. Swedish [14] and British [15] scholars focus on finding out the place and role of energy management in the Business Management System. Despite the different terms of reference, both authors agree that one of the major factors hindering energy efficiency in manufacturing enterprises is relatively low priority given to energy problems as compared to other administration issues. Thus, we can state that the enterprise's energy saving policy is crucial to achieving the ultimate outcome in managing energy conservation and efficiency.

\section{Energy Conservation and Its Place in the Enterprise Policy}

The following is a basic scheme for energy conservation and efficiency management in the industrial sector (Fig.1). The multitude of feasible projects is the basis for making an energy conservation and efficiency program. 
Project choice and implemen-

\begin{tabular}{|c|c|c|}
\hline $\begin{array}{c}\text { Multitude of possible energy } \\
\text { efficiency projects to be im- } \\
\text { plemented }\end{array}$ & tation principles \\
\hline
\end{tabular}

Fig. 1. Basic scheme for energy saving and efficiency program management.

The more projects we chose and implement the greater effect we will achieve by realizing them. The key element in the program management is "choice and implementation principles", which allow many feasible projects to be narrowed and transformed into possible resulting effects. Mathematically, energy efficiency management can be represented as follows:

$I \stackrel{\delta}{\longrightarrow} \tilde{I}$ Where I - is the set of possible projects, each of which alone is feasible for the enterprise; $\widetilde{I}$ - is the set of possible resulting effects; $\delta$ - stands for the possible project choice and implementation principles, which make it possible to pass from I set to $\widetilde{I}$ set.

It seems reasonable that apart from project choice principles we should take into account a number of restrictions, such as funding constraints, technological compatibility, etc. Therefore, we should amplify the mathematic model of energy efficiency management (1) by adding a constraints system:

$\mathrm{I} \longrightarrow \mathrm{I} \mid \mathrm{O}(\mathrm{I}) \in \mathrm{O}$ Where $O(\widetilde{I})$ - are internal and external constraints imposed upon the possible resulting effects $(\widetilde{I})$, which belong to $O$ (the permissible range set of all possible constraints).

Set up mathematically, the project choice principles $\delta$ must be regarded as a function which reflects energy efficiency management target figures, i.e. as a target function. The best value for criterion function must be searched in the possible projects set $I$. The target figures depend on great many factors, which altogether can be generally called "energy saving positioning".

By energy saving positioning we will mean strategic management decisions in relation to place of energy saving in management priorities system of the industry. The decision should me made in compliance with aims, requirements and anticipated result of energy saving program implementation. Energy saving positioning determines energy policy of the enterprise. We can identify three options for energy saving positioning in the enterprise:

1. Energy conservation and energy efficiency as a way to solve certain problems of power supply service. Such positioning implies that energy conservation aims to provide solution to the problems related to rectifying defects in industry's power supply service. It can result in lowering industry's energy consumption both in physical and monetary terms, reduction in energy consumption associated with production of certain types of goods, etc. Therefore, if such energy saving policy is adopted, the factory management team aims to solve current problems in power supply operation.

2. Energy saving and efficiency as a way to increase the industry's performance in investment development programs. Energy conservation in that case is regarded as one of many business lines to increase the industry's performance, together with delivering production technology innovation, upgrading operating machinery, adapting advanced materials, etc. The effect of energy saving declares itself in growing production and commercial performance of the company. Decisions making is based on economic appraisal of commercial effectiveness of different investment patterns. Thus, such energy conservation policy aims to increase production and commercial efficiency of the enterprise.

3. Energy saving and efficiency as a way to solve strategic problems of corporate development. Energy saving and efficiency is considered as a strategic direction to increase competitiveness of the enterprise. Therefore, successful task solution in this field exercises a dominant influence on the corporate strategic targets.

The key features of options for the proposed energy management positioning are listed in Table 1 below.

Table 1: Classification of options for positioning energy conservation in an industry

\begin{tabular}{|l|l|l|l|}
\hline $\begin{array}{l}\text { Possible positions of energy } \\
\text { efficiency in an industry I } \\
\text { comparison tests }\end{array}$ & $\begin{array}{l}\text { 1. Energy saving and efficiency } \\
\text { as a way to solve certain power } \\
\text { supply problems }\end{array}$ & $\begin{array}{l}\text { 2. Energy saving and efficiency as a way } \\
\text { to improve enterprise performance }\end{array}$ & $\begin{array}{l}\text { 3. Energy saving and efficiency } \\
\text { as a way to address enterprise } \\
\text { strategic issues }\end{array}$ \\
\hline Result assessment & $\begin{array}{l}\text { Rectify defects identified in } \\
\text { enterprise energy supply, } \\
\text { optimize energy saving. }\end{array}$ & $\begin{array}{l}\text { Increase manufacturing and economic } \\
\text { performance, boost financial and } \\
\text { economic indicators of the enterprise }\end{array}$ & $\begin{array}{l}\text { Meet the shareholders' } \\
\text { demands and achieve } \\
\text { enterprise' strategic aims }\end{array}$ \\
\hline
\end{tabular}




\begin{tabular}{|l|l|l|l|}
\hline Period of changes & Short-term & Medium-term & Long-term \\
\hline Scope/range of variation & $\begin{array}{l}\text { Rather narrow/ clearly defined } \\
\text { range }\end{array}$ & $\begin{array}{l}\text { Rather wide/ varies according to the } \\
\text { expectations }\end{array}$ & $\begin{array}{l}\text { Global/ varies according to the } \\
\text { expectations }\end{array}$ \\
\hline Management techniques & Project administration & Program control (pipeline of projects). & Strategic management \\
\hline $\begin{array}{l}\text { Funding and recoupment of } \\
\text { expenses }\end{array}$ & $\begin{array}{l}\text { External and internal sources, } \\
\text { project payoff period equals 1-2 } \\
\text { years }\end{array}$ & $\begin{array}{l}\text { External and internal sources, project } \\
\text { payoff period is up to 6 years }\end{array}$ & $\begin{array}{l}\text { External and internal sources, } \\
\text { project payoff period is up to 10 } \\
\text { years }\end{array}$ \\
\hline
\end{tabular}

The policy adopted by the management team makes it possible to identify obligations and target priorities regarding energy conservation and efficiency. It is energy positioning, that defines the enterprise power policy, together with its subsequent plan making, efficiency record and performance management in relation to energy saving measures.

\section{Method to Set Up a Universal Mathematical Problem to Manage Energy Saving Program in the Enterprise}

To solve energy saving and efficiency management practical tasks, let us generate a method to create a universal economic model, which describes positioning-based management of energy saving program in the enterprise. We will understand universal economic model as:

1. A universal mathematical model of energy saving program in the enterprise.

2. Regulations on the use of this model to work out appropriate management decisions.

The method to create universal mathematical model to manage energy saving program in an enterprise comprises a series of steps (Fig.2).

The first step is to set the problem of managing energy saving program, which reflects the energy saving program key elements expressed mathematically. A simplified version of such mathematical model is setting (2).

The second step should refine the target function of the model, for various positioning options of energy saving in the enterprise. A constraints system is developed for each of them.

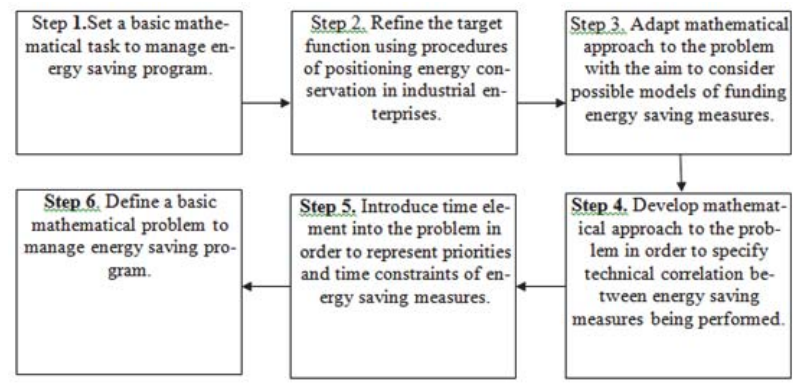

Fig. 2. Method to create a model of universal mathematical problem to manage energy saving program in the enterprise

The third step involves adapting mathematically expressed problem with a view to specify possible funding models for energy saving enterprises. In the fourth step mathematical approach to the problem is developed in order to consider varying degree of technical relation between different energy saving measures being performed. The fifth step introduces time element into the problem in order to represent priorities and time constraints of energy saving measures. The final sixth step expresses a universal mathematical problem to manage energy saving and efficiency program in the enterprise, which comprises all the complements, broadening the basic problem.

\section{Results}

The newly introduced notion "energy positioning" enables the enterprise management group to generalize and classify all possible targets, which must be taken into consideration while setting the target function in mathematical model of managing energy saving program. The proposed general mathematical model can be implemented to make managerial decisions on energy saving and efficiency by companies operating in various industrial sectors and areas. In order to optimize the decisions we use either deterministic or stochastic methods.

In the event that the restrictions are not dependent on the random vector of external parameters, deterministic 
methods are to be used. Alternatively, stochastic methods would be more appropriate, as a certain class of optimization methods characterized with the help of probability distributions in optimum seeking process.

The proposed method to create econometric model will allow us to move from general formal mathematical model of energy saving management to another model, which provides support in making decisions while solving practical energy conservation and efficiency problems in a particular enterprise.

\section{Conclusion}

The proposed approach to managing energy saving program in an enterprise is based on energy saving positioning, which reflects the link between the targets set by its management team and its energy policy. Such an approach aims to increase energy saving efficiency and involves management team into the process from the point of view of priorities set in enterprise development. The project implementation aims to increase competitiveness of enterprises operating in different sectors and areas.

\section{References}

Carlos de Miguel, Alberto Gago, Baltasar Manzano, New developments in energy economics and policy, Energy Economics, Volume 40, Supplement 1, December 2013, Pages S1-S2, ISSN 0140-9883, http://dx.doi.org/10.1016/j.eneco.2013.10.002.

E. Giacone, S. Mancò, Energy efficiency measurement in industrial processes, Energy, Volume 38, Issue 1, February 2012, Pages 331345, ISSN 0360-5442, http://dx.doi.org/10.1016/j.energy.2011.11.054.

Melnik, A.N. Problems and prospects of the formation of clusters in the power engineering [Text] / A.N. Melnik, A.R. Sadriev // World Applied Sciences Journal (Education, Law, Economics, Language and Communication). - 2013. - v. 27. - pp. 194-197.

Sadriev A.R. Problems and prospects of networking mechanism using in energy systems innovation development [Text] / A.R. Sadriev /I Middle-East Journal of Scientific Research. - 2013. V. 17 (10). - pp. 1453-1456.

Nils Weinert, Stylianos Chiotellis, Günther Seliger, Methodology for planning and operating energy-efficient production systems, CIRP Annals - Manufacturing Technology, Volume 60, Issue 1, 2011, Pages 41-44, ISSN 0007-8506, http://dx.doi.org/10.1016/j.cirp.2011.03.015.

Christoph Herrmann, Sebastian Thiede, Process chain simulation to foster energy efficiency in manufacturing, CIRP Journal of Manufacturing Science and Technology, Volume 1, Issue 4, 2009, Pages 221-229, ISSN 1755-5817, http://dx.doi.org/10.1016/j.cirpj.2009.06.005.

Melnik A.N. Methodological Foundations of the Formation of the Energy Strategy of an Enterprise [Text] / A.N. Melnik, L.V. Lukishina, R.R. Khabibrakhmanov // World Applied Sciences Journal. - 2013. - v. 23 (8). - pp. 1085-1089.

Anisimova T.Yu. Analysis of standards in energy management [Text] / T.Yu. Anisimova // Middle-East Journal of Scientific Research. 2013. - v. 13 (5). - pp. 654-657.

IEA, 2012. Policy Pathways: Energy Management Programmes for Industry - Gaining through saving. Paris. OECD/IEA.

Fakhrutdinova E., Severyanov O., Shigabutdinov A., Fakhrutdinov R. The crisis of 1998 in Russia: political intervention and its implications. Life Science Journal 2014; 11(6s): $442-447$.

Joost R. Duflou, John W. Sutherland, David Dornfeld, Christoph Herrmann, Jack Jeswiet, Sami Kara, Towards energy and resource efficient manufacturing: A processes and systems approach, CIRP Annals - Manufacturing Technology, Volume 61, Issue 2, 2012, Pages 587-609, ISSN 0007-8506, http://dx.doi.org/10.1016/j.cirp.2012.05.002.

M.A.R. Lopes, C.H. Antunes, N. Martins, Energy behaviours as promoters of energy efficiency: A 21st century review, Renewable and Sustainable Energy Reviews, Volume 16, Issue 6, August 2012, Pages 4095-4104, ISSN 1364-0321, http://dx.doi.org/10.1016/j.rser.2012.03.034.

Vered Blass, Charles J. Corbett, Magali A. Delmas, Suresh Muthulingam, Top management and the adoption of energy efficiency practices: Evidence from small and medium-sized manufacturing firms in the US, Energy, Volume 65, 1 February 2014, Pages 560-571, ISSN 0360-5442, http://dx.doi.org/10.1016/j.energy.2013.11.030.

Patrik Thollander, Maria Danestig, Patrik Rohdin, Energy policies for increased industrial energy efficiency: Evaluation of a local energy programme for manufacturing SMEs, Energy Policy, Volume 35, Issue 11, November 2007, Pages 5774-5783, ISSN 0301-4215, http://dx.doi.org/10.1016/j.enpol.2007.06.013.

Ralf Martin, Mirabelle Muûls, Laure B. de Preux, Ulrich J. Wagner, Anatomy of a paradox: Management practices, organizational structure and energy efficiency, Journal of Environmental Economics and Management, Volume 63, Issue 2, March 2012, Pages 208-223, ISSN 0095-0696, http://dx.doi.org/10.1016/j.jeem.2011.08.003. 